\title{
Context-related problems and university students' dropout intentions-the buffering effect of personal best goals
}

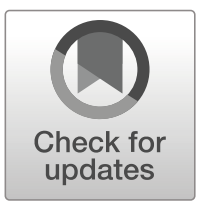

\author{
Lisa Bardach ${ }^{1,2}$ (D) Marko Lüftenegger ${ }^{2,3} \cdot$ Sophie Oczlon $^{3} \cdot$ Christiane Spiel $^{2}$ • \\ Barbara Schober ${ }^{2}$
}

Received: 26 January 2019 / Revised: 6 May 2019 / Accepted: 24 July 2019 /

Published online: 13 August 2019

(C) The Author(s) 2019

\begin{abstract}
This study investigates the effects of contextual and motivational factors as well as, crucially, their interaction in predicting university students' dropout intentions. We focus on contextrelated problems in students' degree program as contextual factors and students' personal best goals (PB goals) as motivational factors. The sample of this study comprised 432 university students $(74.3 \%$ female) enrolled in master's degree programs at Austrian universities. Data was analyzed by means of structural equation modeling and latent moderated structural equation modeling. The results indicated that PB goals were negatively associated with dropout intentions, while context-related problems were positively associated with dropout intentions. In addition, the context-related problems $\times$ PB goals interaction effect proved significant and negatively predicted dropout intentions. By showing that the positive relation between contextrelated problems and dropout intentions can be reversed by increasing PB goals, we provide empirical evidence of the buffering effect of PB goals in the face of context-related problems.
\end{abstract}

Keywords Dropout · University · Personal best goals $\cdot$ Motivation $\cdot$ Context-related problems

\section{Introduction}

Students who drop out of university can experience detrimental economic and psychological consequences of their failure to complete a degree program (e.g., Lundquist et al. 2002). Thus,

Lisa Bardach

lisa.bardach@york.ac.uk

Department of Education, University of York, York YO10 5DD, UK

2 Faculty of Psychology, Department of Applied Psychology: Work, Education, and Economy, University of Vienna, Universitätsstraße 7, 1010 Vienna, Austria

3 Centre for Teacher Education, Department for Teacher Education, University of Vienna,

Porzellangasse 4, 1090 Vienna, Austria 
understanding why students consider withdrawing holds important implications for individual students' wellbeing and is essential to reducing university dropout rates. Accordingly, considerable research efforts have been made in identifying factors that help to explain students' dropout intentions (e.g., Pleskac et al. 2011; Suhlmann et al. 2018; Zając and KomendantBrodowska 2019). In research on university dropout, context-related factors, such as institutional support structures, have been widely investigated as potential predictors of student dropout (e.g., Bettinger and Long 2018; Bergman et al. 2014; Tinto 2006). Furthermore, researchers have paid attention to individual student characteristics such as motivational orientations that make students more or less prone to persisting (e.g., Girelli et al. 2018; Dresel and Grassinger 2013; Suhre et al. 2013). Despite the development of integrated models incorporating context-related and individual factors and studies examining both types of dropout predictors (e.g., Tinto 1975, 1987; Georg 2009; Heublein 2014), the question of how individual and context-related factors interact in predicting students' dropout intentions calls for further exploration. The present study therefore investigates (a) the main effects of structural and individual factors on students' dropout intentions as well as (b) the interaction between these two factors in predicting dropout intentions. With regard to structural factors, we focus on context-related problems students may experience at university and in their study program (e.g., Lundquist et al. 2002). Individual factors are assessed within the motivational framework of personal best goals, i.e., students' tendency to pursue growth-oriented goals in their degree program (e.g., Martin 2006).

\section{Students' intention to drop out-the role of context-related and motivational factors}

The decision to drop out of one's current study program can best be understood as a prolonged, complex, multi-faceted process in which different influencing factors accumulate to create a constellation of problems that makes leaving seem inevitable (e.g., Heublein 2014; Ozga and Sukhnandan 1998; Wilcox, Winn, \& Fyvie-Gauld, 2005). A wealth of empirical and conceptual literature currently exists helping us better understand the aspects that affect students' intentions to stay or leave. Specifically, researchers commonly distinguish between structural features and individual student features.

\section{Study dropout and context-related factors}

What structural issues ultimately shape university students' thoughts about staying or leaving? It has been suggested that structural characteristics of institutions, such as size and selectivity, influence student dropout outcomes (Berger and Milem 2000). More precisely, negative relations between both size and selectivity and student dropout have been reported (e.g., Kim 2007; Titus 2004; Ryan 2004). Empirical evidence also indicates that institutional expenditure on student services is negatively associated with student dropout (Chen 2012). Furthermore, research reveals that having a clear mission and an atmosphere in which all students are welcome enhances a university's ability to retain students (Woodard, Mallory, \& De Luca, 2001). By contrast, a lack of support from faculty and insufficiently responsive faculty members are assumed to increase the likelihood that students will think of leaving the university (Lundquist et al. 2002). Moreover, it has been shown that a lack of information can cause premature study termination (e.g., Heublein 2014), whereas transparent degree program 
requirements in the curriculum enhance completion (Suhre et al., 2013). In sum, a number of institutional characteristics have been found to be key to grasping students' intentions to persist or drop out of their degree program. However, this view has also been complemented by research efforts exploring individual student characteristics. Here, for instance, researchers have examined students' financial situation, inability to cope with the performance-related demands of the higher education institution, social competence, use of learning strategies, and weak commitment to a degree program in general as factors that might be related to dropout (e.g., Georg 2009; Heublein 2014; Schiefele et al. 2007). A further set of individual characteristics that has been studied in research on why students consider withdrawing from their field of study or intend to persist is students' motivation (e.g., Baier et al. 2016; Dresel and Grassinger 2013).

\section{University dropout and personal best goals}

Evidence exists that motivation, in the form of self-concept in one's field of study, the subjectively perceived value of one's degree program prior to beginning university, and changes in motivation over the first year, predict students' dropout intentions (Dresel and Grassinger 2013; for research on perceived competence and dropout, see also, e.g., Litalien and Guay 2015). Similarly, Schiefele et al. (2007) demonstrated that differences in maladaptive motivational patterns between students who ended their study programs prematurely and their peers who completed their programs already existed at the point of university entry. Furthermore, higher levels of self-efficacy have been shown to augment university students' intentions to persist (Baier et al. 2016; Hsieh et al. 2007; for a meta-analytic review, see Robbins et al. 2004), and intrinsic motivation has been identified as a factor that can counteract dropout intentions (e.g., Rump et al. 2017). In conclusion, the current state of research suggests that motivational factors have an impact on university students' withdrawal intentions. While a number of motivational variables have already been examined, as reviewed above, the motivational construct of personal best goals (e.g., Martin 2006; Martin et al. 2016) has not yet been investigated in research on student dropout.

Personal best goals (PB goals) are defined as growth-oriented goals towards improving one's previous best (Martin et al. 2016), such as spending more time working on a current assignment than on the previous assignment or attaining a higher score on the next test than on a previous one (Martin 2006; Martin 2013). Four dimensions of PB goals, which together constitute an overall PB goal orientation, have been initially proposed. First, PB goals are challenging, as they must be at least higher than one's previous best level of performance (Martin 2006). Second, PB goals incorporate a clear standard to aim for and are thus specific goals. However, PB goals are more than the mere attainment of a given standard, as PB goals involve a personalized standard set in relation to one's own previous level of performance. This personalized element of PB goals is expressed in the third and fourth dimensions: competitive self-reference and self-improvement. While the former describes a competitive orientation focused on competing with one's own previous performance, the latter taps an individual's striving to advance beyond previous levels of performance (Martin 2006). In more recent work, self-improvement goals alone have been applied as a measure of students' PB goals (e.g., Liem et al. 2012; Martin et al. 2016).

Key motivational constructs that are theoretically connected to and underpin the PB goal construct include the concepts of goal content (Austin and Vancouver 1996), achievement goals (Elliot 2006), and goal-setting (Locke and Latham 2002; for a thorough discussion of the theoretical embedding of PB goals, see Martin 2006, 2011; also see Liem et al. 2012). 
According to a goal content perspective, meeting a challenging achievement (or improvement) standard is an important task-based goal that individuals strive for (Austin and Vancouver 1996). This is reflected in PB goals' focus on self-improvement and the attainment of optimally challenging outcomes (Liem et al. 2012). In addition, PB goals share critical features with achievement goals. Adopting a $3 \times 2$ model of achievement goals that distinguishes among self-approach and self-avoidance, task-approach and task-avoidance, and otherapproach and other-avoidance goals (Elliot et al. 2011), there is a clear connection between PB goals and self-approach goals. Both self-approach goals and PB goals are approach-based goals with concrete target outcomes and both are evaluated against standards that build upon one's previous best performance and/or future potential attainment. However, while selfapproach goals tend to focus on product-related outcomes (e.g., the results of an exam), PB goals concentrate on both product outcomes and process outcomes (e.g., spending more time working on a current assignment than before) (Martin 2011).

Finally, Martin $(2006,2011)$ identified a connection between PB goals and individuals' goal-setting capacity (Locke and Latham 2002). Given that PB goals include specific target outcomes slightly above one's previous best performance, individuals must be able to set specific goals with a difficulty level of optimal distance from their current ability level (Martin 2006, 2011). Setting PB goals can thus also be viewed as a regulation strategy and linked to models of self-regulation (e.g., Zimmerman's cyclic model of self-regulated learning, which includes a goal-setting component, e.g., Zimmerman and Moylan 2009).

A number of studies have linked PB goals to adaptive educational outcomes, such as achievement, class participation, and enjoyment of school, in samples of school-aged students (e.g., Khajavy, Bardach, Hamedi, \& Lüftenegger, 2018; Martin 2006; Martin 2013; Martin and Elliot 2016). Moreover, PB goals have been found to be related to secondary school students' persistence and academic intentions, e.g., the intention to complete school (e.g., Martin and Liem 2010; Martin et al. 2016; Martin 2006). Other studies have shown that PB goals positively predict secondary school students' engagement (e.g., Martin et al. 2016; Burns, Martin, \& Collie, 2019). In contrast to the wealth of empirical evidence on the adaptive nature of PB goals derived from studies of secondary education, PB goals have, to the best of our knowledge, not yet been explored in samples of university students.

We had three reasons for concentrating on PB goals as the individual motivational factor in our study. First, PB goals represent a rich motivational blend, or melting pot of adaptive motivational constructs (e.g., achievement goals, goal-setting; Martin 2006, 2011). Rather than focusing on motivational constructs that have already been extensively studied in samples of university students (e.g., achievement goals), we deemed it more valuable to introduce the PB goal construct to research at this educational level. We see no reason to believe that the value of the PB goal construct should be restricted to the school context, as this is not the case with other (motivational) constructs conceptually related to PB goals (achievement goals, goalsetting, goal content, self-regulation). Second, the positive relations found in research on secondary school students to outcomes such as persistence, academic intentions, and engagement (e.g., Martin and Liem 2010; Martin et al. 2016; Martin 2006) point to the particular promise of including PB goals in the network of constructs investigated in research on university dropout. Third, the PB goal construct incorporates a set of concrete features, such as specific goals and challenging goals, that can be promoted via interventions (see e.g., Martin et al. 2014). Thus, accumulating evidence on PB goals' functioning in samples of university students can be seen as a first step towards informing future interventions in higher education and ultimately improving practice. 


\section{The present investigation}

Relying on a cross-sectional correlational research design, the current work addressed two major research questions. Firstly, what role do structural factors and individual motivational factors in terms of PB goals play for students' thoughts about quitting their studies prematurely? Drawing on the existing body of literature on dropout (e.g., Bettinger and Long 2018; Bergman et al. 2014; Tinto 2006), we hypothesized that structural factors, conceptualized as context-related problems in one's degree program, positively predict dropout intentions (hypothesis 1a) (e.g., Chen 2012; Heublein 2014; Lundquist et al. 2002). Furthermore, building on findings on the adaptive outcomes of PB goals derived from samples of secondary school students (e.g., Martin 2006; Martin and Liem 2010; Martin et al. 2016), we expected PB goals to be negatively associated with dropout intentions (hypothesis $1 \mathrm{~b}$ ). In addition to the two main effects for context-related problems and PB goals, we secondly sought to explore the interaction between structural components and PB goals - Does the interaction between structural factors and PB goals predict dropout intentions? Here, we assumed that higher levels of beneficial PB goal orientations buffer the negative effect of context-related problems on dropout intentions. Succinctly stated, we hypothesized that the interaction term between context-related problems and PB goals would be negatively related to dropout intentions (hypothesis 2). This would imply that higher levels of PB goals act as a protective mechanism, making students less likely to intend to quit their degree program even when they are exposed to context-related problems.

\section{Method}

\section{Sample}

A total of 432 master's degree students participated in the present study ( $74.3 \%$ female, $23.6 \%$ male, $2.1 \%$ did not want to assign themselves to the categories of male or female). The students came from 12 Austrian universities and were enrolled in a wide range of master's study programs, with the majority $(56 \%)$ in the humanities or social sciences. Students' mean age was $26.55(S D=5.72)$ years and they had completed $3.35(S D=2.43)$ semesters of their master's degree on average. If students were pursuing more than one degree programs, they were asked to refer to only one of their degree programs when answering the questionnaire. Of the 432 participants, $71.5 \%$ indicated their nationality as Austrian, 19.2\% were German, and the rest were from other countries. Data for this study was collected via an online survey. The link to the online survey was distributed via internet platforms and social media groups for students. All students participated voluntarily and received no compensation for their participation. The data was collected in accordance with the EU General Data Protection Regulation; anonymity and no unwarranted access to the data were assured.

\section{Measures}

We used three scales to assess the constructs investigated in our study, i.e., PB goals, contextrelated problems, and dropout intentions (see descriptions below). The items for all scales were assessed using a 6-point response format, ranging from 1, "strongly agree" to 6, "strongly disagree". For ease of interpretation, items were recoded such that higher values reflected greater agreement with the presented statements. 


\section{PB goals}

Sixteen items from Martin (2006) were used to measure students' PB goals. The original items were adapted slightly to focus on the university context rather than schoolwork. The scale included items for the four domains of PB goals: specific goals (4 items, e.g., "I get a clear idea about specific things I'm trying to achieve in tasks for my degree program"; $\alpha=.82$ ), challenging goals (4 items, e.g., "When I am working on tasks for my degree program, I set challenges for myself"; $\alpha=.89$ ), competitively self-referenced goals (4 items, e.g. "I am in competition with myself more than with other students"; $\alpha=.81$ ), and self-improvement goals (4 items, e.g. "When I am working on a task for my degree program, I try to do it better than I've done before"; $\alpha=.88$ ). Researchers studying PB goals tend to apply only the selfimprovement items (e.g., Martin and Liem 2010; Martin et al. 2016); however, we decided to use the items for all four domains as we believe that a more fine-grained conceptualization allows us to more comprehensively study the PB goal construct.

\section{Dropout intentions}

The scale to measure dropout intentions was based on Dresel and Grassinger (2013). While the original scale referred to both university dropout intentions and the intention to change one's major, our adapted version exclusively focused on dropout intentions. Three items were administered (e.g., "I often think about dropping out of my current degree program" or "The thought often crosses my mind that my current degree program is not for me"; $\alpha=.86$ ).

\section{Context-related problems}

Context-related problems were assessed with a self-constructed scale capturing structural issues that have been found to be related to university dropout in previous research (e.g., Lundquist et al. 2002; Heublein 2014). Following a short introduction ("In my master's degree program, there are the following context-related problems ..."), students rated the extent to which each of a set of problems were present in their current degree program (four items, i.e., "Lack of support from lecturers in classes", "Not enough information on the study program available", "Not enough opportunities to exchange information with other students", "Inappropriate dates of seminars/lectures, dates of different seminars/lectures are not sufficiently coordinated"; $\alpha=.74)$.

\section{Statistical analyses and missing data}

All analyses were performed in Mplus version 7.3 (Muthén and Muthén 1998-2015) via structural equation modeling using the robust maximum likelihood estimator (MLR) estimator. The amount of missing data in the current study ranged between 0 and $2.3 \%$ on the item level for all constructs. We applied a full information maximum likelihood (FIML; Enders and Bandolos 2001) to deal with the missing data.

Confirmatory factor analytic (CFA) models were specified to test the dimensionality of the scales assessing PB goals, dropout intentions, and context-related problems. In preliminary analyses, we also tested for the effects of a set of potentially influencing variables-i.e., extent of employment (hours/week), students' current semester, and whether or not students were also pursuing one or more further study programs - on 
dropout intentions. If we found an effect, the corresponding variable was included as a control variable in the main analyses.

We relied on a two-step approach to answer our two research questions (Maslowsky et al. 2015; see also Klein and Moosbrugger 2000; Muthén 2012). For the first research question (main effects of context-related problems and PB goals), we estimated the effects of context-related problems and PB goals on dropout intentions in a structural equation modeling approach. Building on this structural equation model, the second research question (interaction between context-related problems and PB goals in predicting dropout intentions) was addressed by setting up a latent moderated structural equation model (LMS) using the XWITH command (Klein and Moosbrugger 2000; Maslowsky et al. 2015). In this model, we estimated both the main effects of each predictor (PB goals and context-related problems) and the latent interaction between them. Unlike more widely used conventional approaches to testing interactions, i.e., ordinary least squares regression, LMS' latent variable approach gives interaction estimates unattenuated by measurement error (e.g., Little et al. 2006; Maslowsky et al. 2015).

The model fit of the CFAs and the model for research question 1 (hypotheses 1a and 1b) was evaluated by means of the comparative fit index (CFI) and root mean square error of approximation (RMSEA). Typical cut-off scores taken to reflect excellent and adequate fit to the data were considered: (a) CFI $\geq .95$ and $\geq .90$ and (b) RMSEA $\leq .06$ and $\leq .08$ (Hu and Bentler 1999; Marsh et al. 2004), respectively. As CFI, RMSEA, and other fit indices generally used to interpret the fit of structural equation models have not yet been developed for LMS models, we assessed the overall fit of the LMS (model for research question 2) by relying on the procedures described by Maslowsky and colleagues (Maslowsky et al. 2015; see also Klein and Moosbrugger 2000; Muthén 2012). First, CFI and RMSEA values were obtained from the model for research question 1. Second, we employed a log-likelihood ratio test to compare the relative fit of the model for research question 1 (i.e., the null model in which the interaction was not estimated and therefore assumed to be zero) and the model for research question 2 (i.e., the alternative model in which the interaction was estimated). The log-likelihood ratio test is used to determine whether the more parsimonious model that does not estimate the interaction effect exhibits a significant loss of fit relative to the more complex model including the interaction term (Satorra 2000; Satorra and Bentler 2001). If the model without the interaction fits the data well and the log-likelihood ratio test indicates that the model without the interaction represents a significant loss in fit relative to the model with the interaction, it is reasonable to conclude that the model with the interaction is a well-fitted model (Maslowsky et al. 2015).

We present standardized regression coefficients when reporting the results for research questions 1 and 2. Because Mplus does not provide standardized regression coefficients for LMS models, we standardized the data prior to analysis to obtain standardized beta coefficients (e.g., Klein and Moosbrugger 2000; Maslowsky et al. 2015). We furthermore report $R^{2}$, i.e., the share of variance explained by the latent interaction and the total explained variance in the dependent variable (dropout intentions). While $R^{2}$ for the model without the interaction (model for research question 1) could be obtained from the Mplus output, we calculated $R^{2}$ for the model with the interaction term (model for research question 2) using the formula provided by Maslowsky et al. (2015). Finally, we calculated the difference between these two $R^{2}$ values, yielding the proportion of $R^{2}$ attributable to the interaction term. 


\section{Results}

Bivariate correlations among all scales are presented in Table 1. The results of the CFAs for the measurement models for PB goals, context-related problems, and dropout intentions indicated a good level of fit to the data for all scales (see Table 2). It should be noted that for PB goals, we followed Martin (2006; see also, e.g., Khajavy et al., 2018) and used a second-order model in which the four goals together represent an individual PB goal orientation. Preliminary analyses indicated no effect of extent of employment (hours/week), whether or not students were also pursuing one or more further study programs, and students' current semester of studies on dropout intentions. Therefore, the main analyses (see below) were conducted without controlling for these variables.

The model for research question 1 exhibited a good level of fit to the data, $\chi^{2}=429.043$ (223), $\mathrm{CFI}=0.95, \mathrm{TLI}=0.94, \mathrm{RMSEA}=0.046$, and $\mathrm{SRMR}=0.052$. Both context-related problems and $\mathrm{PB}$ goals significantly predicted dropout intentions, with context-related problems positively related $(\hat{\beta}=0.294, p<.01)$ and $\mathrm{PB}$ goals negatively related to students' intentions to drop out $(\hat{\beta}=-0.245, p<.01)$. Thus, both hypothesis $1 \mathrm{a}$ and hypothesis $1 \mathrm{~b}$ were supported. The model explained $16.4 \%$ of the variance in dropout intentions. Next, we estimated the model for research question 2 including the interaction term. In order to determine the relative fit of the model with the interaction (model for research question 2) compared to the model without the interaction (model for research question 1), we used a loglikelihood ratio test to compare the log-likelihood values of the two models. The test yielded a log-likelihood difference value of $D=7.452$. The difference in free parameters between the model for research question 1 (223) and the model for research question 2 (224) was equal to 1. Hence, we used a df value of 1 in the log-likelihood ratio test. The log-likelihood ratio test based on a chi-square distribution was significant $(p<.001)$, revealing that the model without the interaction effect (model for research question 1) represented a significant loss in fit relative to the model with the interaction effect (model for research question 2). Therefore, we could conclude that the model for research question 2 also fit the data well (e.g., Maslowsky et al. 2015; Satorra and Bentler 2001). The context-related problems $\times$ PB goals interaction effect proved significant $(\beta=-0.353, p<.01)$, indicating that the association between context-related problems and dropout intentions decreases and even becomes negative as PB goals increase. Hence, hypothesis 2 was empirically supported.

Lastly, in order to interpret the size of the interaction effect, we calculated $R^{2}$ for the model for research question 2 using the method described by Maslowsky et al. (2015). This yielded a value

Table 1 Bivariate correlations among all variables

\begin{tabular}{|c|c|c|c|c|c|c|c|}
\hline Variable & 1. & 2. & 3. & 4. & 5. & 6. & 7. \\
\hline 1. PB goal orientation (2nd order) & - & & & & & & \\
\hline 2. PB subscale: specific goals & $.81 * *$ & - & & & & & \\
\hline 3. PB subscale: challenging goals & $.85^{* *}$ & $.66 * *$ & - & & & & \\
\hline 4. PB subscale: self-impr. goals & $.84^{* *}$ & $.58 * *$ & $.66^{* *}$ & - & & & \\
\hline 5. PB subscale: Comp. self-ref. goals & $.73^{* *}$ & $.41 * *$ & $.41 * *$ & $.49 * *$ & - & & \\
\hline 6. Context-related problems & $-.11 *$ & $-.10 *$ & $-.10 *$ & -.06 & -.09 & - & \\
\hline 7. Dropout intentions & $-.28 *$ & $-.29 * *$ & $-.25 * *$ & $-.21 * *$ & $-.17 * *$ & $.28 * *$ & - \\
\hline
\end{tabular}

$N=432$ university students

$* p<.05 ; * * p<.01$ 
Table 2 CFA model results for all scales

\begin{tabular}{lllllll}
\hline & $\chi^{2}$ & df & CFI & TLI & RMSEA & SRMR \\
\hline PB goals measurement model & $261.89^{*}$ & 100 & 0.94 & 0.93 & 0.061 & 0.056 \\
Context-related problems measurement model & 4.79 & 2 & 0.99 & 0.97 & 0.000 & 0.057 \\
Dropout intentions measurement model & 0.00 & 00 & 1.00 & 1.00 & 0.000 & 0.000 \\
\hline
\end{tabular}

$\chi^{2}=$ Yuan-Bentler robust test statistic, $\mathrm{CFI}=$ comparative fit index, TLI $=$ Tucker-Lewis index, RMSEA $=$ root mean square error of approximation, $\mathrm{SRMR}=$ standardized root mean square residual. Note that the dropout intentions measurement model is saturated and thus has a perfect fit

$* p<0.001$

of $R^{2}=0.187$, meaning that $18.7 \%$ of the variance in dropout intentions was explained. Subtracting the $R^{2}$ of the model without an interaction from the $R^{2}$ of the model with an interaction yielded an $R^{2}$ value of .023 for the interaction, i.e., an additional $2.3 \%$ of variance in dropout intentions was explained by the interaction between context-related problems and PB goals.

\section{Discussion}

Student dropout has long been and continues to be one of the most important issues facing the higher education community (e.g., Jones and Braxton 2009; O'Keeffe 2013; Tinto 2006; Vossensteyn et al. 2015). The purpose of this study was to provide a better understanding of university students' intentions to withdraw from their degree program by investigating the predictive power of both structural and individual features. Moving towards a more integrated perspective on dropout intentions, we specifically paid attention to the interplay between personal orientations and students' perceptions of their contextual surroundings. The present study thus explored how context-related problems (e.g., Heublein 2014) and students' focus on specific, challenging, self-referenced, and self-improvement-based goals for their degree program (e.g., Martin 2006) interact in predicting students' thoughts about a premature departure. In this section, we summarize and interpret our three major findings, briefly highlight practical implications, and finish by considering the limitations of our work along with new issues for future research on university dropout.

First, in accordance with a large body of prior research on the role of institutional factors (e.g., Chen 2012; Jones and Braxton 2009; Lundquist et al. 2002), this study confirmed that context-related problems predict dropout intentions (hypothesis 1a). Concretely, inadequate study conditions, such as a lack of information on the study program or insufficient support from lecturers, increased students' thoughts about dropping out of their degree program. Although the contextual features investigated here are only a few of the many factors shaping students' intentions to quit, our study points to the value of addressing university dropout from an institutional perspective (see also, e.g., Chen 2012).

Second, shifting our focus to individual characteristics, we found students' PB goals to be negatively related to thoughts about dropping out (hypothesis 1b). This result is important for several reasons. On the one hand, it supports the relevance of PB goals in studying university dropout, thus expanding the nomological network of motivational predictors within research on dropout intentions. Studies in this line of research have predominantly concentrated on classical and well-established motivational aspects, such as self-efficacy or value beliefs (e.g., Baier et al. 2016; Dresel and Grassinger 2013; Robbins et al. 2004). Hence, empirical evidence on the role 
of the comparatively more recently developed motivational construct of PB goals complements the insights gained by applying classical motivational theories and elicits fresh understandings about the relation between motivation and dropout. In addition, our study makes a contribution to the current research landscape of PB goals. Whereas PB goals have been linked to persistence and academic aspirations, e.g., the intention to complete school (Martin and Liem 2010; Martin et al. 2016; Martin 2006), no study has yet shed light on whether PB goals affect the other side of the coin, i.e., intentions to dropout. Our results on the significance of PB goals in this regard thus strengthen this construct's theoretical and empirical foundation. Furthermore, previous research on PBs has been conducted in schools, with PB goals in adult populations such as university students remaining unexplored. Accordingly, our study, which relies on a sample of university students, expands this line of research and provides evidence for the factorial validity of PB goals in this age group. Moreover, the negative association we found between PB goals and dropout intentions provides initial support for their value for studies in the university context.

Our results concerning PB goals and dropout intentions are also of practical relevance. In comparison with the less tangible and rather stable individual characteristics associated with dropout, e.g., students' financial situation or cognitive abilities, non-cognitive factors such as motivation tend to be more responsive to change via interventions (e.g., Credé et al. 2016; Robbins et al. 2004). Our findings on the role of PB goals in decreasing dropout intentions therefore highlight opportunities for interventions promoting academic persistence. More specifically, our findings suggest that supporting students in setting goals for tasks in their studies that are specific, challenging, selfreferenced and inherently linked to self-improvement rather than comparing themselves to others (e.g., Martin 2006) might counteract the development of dropout intentions.

Third, bringing individual and structural aspects together, the results of our study revealed a significant interaction between context-related problems and PB goals in predicting dropout intentions (hypothesis 2). Concretely, this means that the relation between context-related problems and dropout intentions becomes negative as PB goals increase. Considering that the main effect of context-related problems on dropout intentions was positive, i.e., higher context-related problems were related to higher dropout intentions, we interpret the results for the interaction as indicating that the positive relation between context-related problems and dropout intentions can be reversed by increasing PB goals. In our opinion, this finding is the key contribution of the current study and holds implications for both researcher and practitioners. From a research standpoint, our work emphasizes the value of studying how constructs interact with each other to predict the widely studied phenomenon of university dropout. The interplay of different factors, including individual and structural components, has long been recognized in this research area (e.g., Heublein 2014). Nonetheless, to our knowledge, potential interactions have not yet been empirically investigated. Although our research is limited to just two of the host of aspects that play a role in the development of dropout intentions, it shows that modeling interactions can deliver important insights complementing those provided by examinations of main effects.

For practitioners, e.g., lecturers and other university staff, our findings imply that equipping students with PB goal-setting strategies could buffer against the intentions to leave that students might develop in the face of inevitable structural shortcomings. Does this mean that the relevance of our first finding - that context-related problems increase dropout intentions - and the recommendations for overcoming context-related problems given above can be neglected or even ignored? Should efforts be solely concentrated on fostering individual motivational characteristics such as PB goals? We clearly do not advise this. However, we are aware of the difficulties of initiating and sustainably implementing systemic-level changes at university due to the oftenlimited financial resources and dependence on (educational) policy forces, among other factors. 
As such, supporting students' PB goals appears to be a promising strategy that can be more easily applied than fundamental institutional changes and can be carried out by lecturers and advisors.

\section{Limitations and future lines of research}

The current work has some shortcomings that need to be discussed and that suggest directions for future research. While the analyses employed in this study, structural equation modeling and latent moderated structural equation modeling, are well-suited methodologies with numerous benefits, we are aware that the methods we use to address our research questions serve as lenses with a particular focus. Consequently, we argue that future studies on dropout intentions and influencing factors use multiple methods, e.g., interviews or focus groups alongside quantitative measures, as well as person-centered approaches (e.g., De Clercq et al. 2017). It might also be crucial to integrate different actors, i.e., lecturers and study program directors in addition to students, in order to fully appreciate the intricacies of this issue from different perspectives. A further limitation of the study concerns the fact that we relied on dropout intentions as a proxy for university dropout, but did not investigate actual dropout behavior (see, e.g., Heublein 2014). We thus recommend that future research test the proposed predictors in samples of non-completers. However, it should be noted that the relationship between dropout intention and actual dropout has long been emphasized in the literature (e.g., Bean and Metzner 1985; Bäulke et al. 2018; Cabrera et al. 1993; Mashburn 2000), indicating that studying dropout intentions is still a valuable approach (see also, e.g., Litalien and Guay 2015). In addition, we focused on master's students, and relying on a sample from this population might have influenced our findings. Nonetheless, we cautiously propose that, across educational settings, context-related problems might be positively related to dropout intentions and PB goals, as beneficial personal motivational orientations, might be negatively related to dropout intentions. Still, we speculate that the buffering effect of PB goals might have been more pronounced in this sample than it would have been in a sample of bachelor's students. Master's students are already far along in their studies and already have a bachelor's degree. We further suggest that a certain percentage of master's students might have already been exposed to contextrelated problems in their bachelor's studies, and those who persevered despite these problems might have developed specific strategies and motivational patterns - such as a higher PB goal orientation - that enabled them to succeed and avoid (intending to) drop out from their first degree. Hence, when exposed to context-related problems during their master's degree, they might immediately activate these protective mechanisms to buffer against the negative consequences of these problems, such as the intention to drop out. Of course, these suggestions are clearly speculative. We therefore highly encourage future studies to replicate our work in samples from other levels of higher education (e.g., bachelor's students, doctoral students) to explore whether the same pattern of results can be obtained in different samples.

Finally, we restricted our focus in terms of predictors of dropout intentions to contextrelated problems and PB goals. Although the choice of these two predictors was theoretically justified and empirically supported by the study's findings, further research is encouraged to examine the effects of other contextual characteristics, such as institutional culture or motivational climate (e.g., Skaalvik and Skaalvik 2013; Bardach et al 2019a; Bardach 2019b), and other individual characteristics. With regard to individual characteristics, it might be particularly illuminating to expand the scope to specific personality traits, such as self-compassion (e.g., Patzak et al 2017), or motivational facets not yet considered in research on university dropout, such as implicit theories or achievement goals (e.g., Lüftenegger \& Chen, 2017; Bardach et al 2019c; Darnon et al. 2018). 


\section{Conclusions}

University student dropout, its reasons, and its implications have been studied extensively over the last few decades. In the present study, we explored the predictive function of context-related problems and PB goals as well as the interaction between structural and individual features. Our findings indicate that both the context and PB goals as individual features matter for students' dropout intentions, and most importantly, that their interaction further predicts dropout intentions. Whereas context-related problems increased dropout intentions and PB goals decreased them, the interaction between these two components buffered the positive effect of context-related problems on dropout intentions and even reversed it. As such, the present work contributes to the current state of research on dropout intentions and offers implications for educational practice.

Open Access This article is distributed under the terms of the Creative Commons Attribution 4.0 International License (http://creativecommons.org/licenses/by/4.0/), which permits unrestricted use, distribution, and reproduction in any medium, provided you give appropriate credit to the original author(s) and the source, provide a link to the Creative Commons license, and indicate if changes were made.

\section{References}

Austin, J. T., \& Vancouver, J. B. (1996). Goal constructs in psychology: structure, process, and content. Psychological Bulletin, 120(3), 338-375. https://doi.org/10.1037/0033-2909.120.3.338.

Baier, S. T., Markman, B. S., \& Pernice-Duca, F. M. (2016). Intent to persist in college freshmen: the role of selfefficacy and mentorship. Journal of College Student Development, 57(5), 614-619. https://doi.org/10.1353 /csd.2016.0056.

Bardach, L., Lüftenegger, M., Yanagida, T., Schober, B., \& Spiel, C. (2019a). The role of within-class consensus on mastery goal structures in predicting socio-emotional outcomes. British Journal of Educational Psychology, 89, 239-258. https://doi.org/10.1111/bjep.12237.

Bardach, L., Lüftenegger, M., Yanagida, T., Spiel, C., \& Schober, B. (2019b). Achievement or agreement - which comes first? Clarifying the temporal ordering of achievement and within-class consensus on classroom goal structures. Learning and Instruction, 61, 72-83. https://doi.org/10.1016/j.learninstruc.2019.01.003.

Bardach, L., Popper, V., Hochfellner, E., \& Lüftenegger, M. (2019c). Associations between vocational students' perceptions of goal structures, mastery goals, and self-efficacy in five subjects - practical relevance as a potential mediator. Empirical Research in Vocational Education and Training, 11(9). https://doi.org/10.1186 /s40461-019-0084-0.

Bäulke, L., Eckerlein, N., \& Dresel, M. (2018). Interrelations between motivational regulation, procrastination and college dropout intentions. Unterrichtswissenschaft, 46(4), 461-479. https://doi.org/10.1007/s42010018-0029-5.

Bean, J. P., \& Metzner, B. S. (1985). A conceptual model of nontraditional undergraduate student attrition. Review of Educational Research, 55(4), 485-540. https://doi.org/10.3102/00346543055004485.

Berger, J. B., \& Milem, J. F. (2000). Organizational behavior in higher education and student outcomes. In J. C. Smart (Ed.), Higher education: handbook of theory and research (Vol. XV, pp. 268-338). New York: Springer.

Bergman, M., Gross, J. P., Berry, M., \& Shuck, B. (2014). If life happened but a degree didn't: examining factors that impact adult student persistence. The Journal of Continuing Higher Education, 62(2), 90-101. https://doi.org/10.1080/07377363.2014.915445.

Bettinger, E. P., \& Long, B. T. (2018). Mass instruction or higher learning? The impact of college class size on student retention and graduation. Education Finance and Policy, 13(1), 97-118. https://doi.org/10.1162 ledfp_a_00221.

Burns, E. C., Martin, A. J., \& Collie, R. J. (2019). Understanding the role of personal best (PB) goal setting in students' declining engagement: A latent growth model. Journal of Educational Psychology, 111, 557-572. https://doi.org/10.1037/edu0000291. 
Cabrera, A. F., Nora, A., \& Castaneda, M. B. (1993). College persistence: structural equations modeling test of an integrated model of student retention. Journal of Higher Education, 64(2), 123-139. https://doi.org/10.2307 12960026.

Chen, R. (2012). Institutional characteristics and college student dropout risks: a multilevel event history analysis. Research in Higher Education, 53(5), 487-505. https:/doi.org/10.1007/s11162-011-9241-4.

Credé, M., Tynan, M. C., \& Harms, P. D. (2016). Much ado about grit: a meta-analytic synthesis of the grit literature. Journal of Personality and Social Psychology, 113(3), 492-511. https://doi.org/10.1037 /pspp0000102.

Darnon, C., Jury, M., \& Aelenei, C. (2018). Who benefits from mastery-approach and performance-approach goals in college? Students' social class as a moderator of the link between goals and grade. European Journal of Psychology of Education, 4(4), 713-726. https://doi.org/10.1007/s10212-017-0351-z.

De Clercq, M., Galand, B., \& Frenay, M. (2017). Transition from high school to university: a person-centered approach to academic achievement. European Journal of Psychology of Education, 32(1), 39-59. https://doi. org/10.1007/s10212-016-0298-5.

Dresel, M., \& Grassinger, R. (2013). Changes in achievement motivation among university freshmen. Journal of Education and Training Studies, 1, 159-173. https://doi.org/10.11114/jets.v1i2.147.

Elliot, A. J. (2006). The hierarchical model of approach-avoidance motivation. Motivation and Emotion, 30(2), 111-116. https://doi.org/10.1007/s11031-006-9028-7.

Elliot, A. J., Murayama, K., \& Pekrun, R. (2011). A 3x2 achievement goal model. Journal of Educational Psychology, 103(3), 632-648. https://doi.org/10.1037/a0023952.

Enders, C. K., \& Bandolos, D. L. (2001). The relative performance to full information maximum likelihood estimation for missing data in structural equation models. Structural Equation Modeling, 8(3), 430-457. https://doi.org/10.1207/S15328007SEM0803_5.

Georg, W. (2009). Individual and institutional factors in the tendency to drop out of higher education: a multilevel analysis using data from the Konstanz Student Survey. Studies in Higher Education, 34(6), 647-661. https://doi.org/10.1080/03075070802592730.

Girelli, L., Alivernini, F., Salvatore, S., Cozzolino, M., Sibilio, M., \& Lucidi, F. (2018). Coping with the first exams: Motivation, autonomy support and perceived control predict the performance of first-year university students. Journal of Educational, Cultural and Psychological Studies, 18(18), 165-185. https://doi. org/10.7358/ecps-2018-018-gire.

Heublein, U. (2014). Student drop-out from German higher education institutions. European Journal of Education, 49(4), 497-513. https://doi.org/10.1111/ejed.12097.

Hsieh, P., Sullivan, J. R., \& Guerra, N. S. (2007). A closer look at college students: self-efficacy and goal orientation. Journal of Advanced Academics, 18(3), 454-476.

Hu, L., \& Bentler, P. M. (1999). Cutoff criteria for fit indexes in covariance structure analysis: conventional criteria versus new alternatives. Structural Equation Modeling: A Multidisciplinary Journal, 6(1), 1-55. https://doi.org/10.1080/10705519909540118.

Jones, W. A., \& Braxton, J. M. (2009). Cataloging and comparing institutional efforts to increase student retention rates. Journal of College Student Retention: Research, Theory \& Practice, 11(1), 123-139. https://doi.org/10.2190/CS.11.1.g.

Khajavy, G. H., Bardach, L., Hamedi, S. M., \& Lüftenegger, M. (2018). Broadening the nomological network of classroom goal structures using doubly latent multilevel modeling. Contemporary Educational Psychology, 52, 61-73. https://doi.org/10.1016/j.cedpsych.2017.10.004.

Kim, D. B. (2007). The effect of loans on students' degree attainment: differences by student and institutional characteristics. Harvard Educational Review, 77, 64-100. https://doi.org/10.17763/haer.77.1.n14t6910q8292784.

Klein, A., \& Moosbrugger, H. (2000). Maximum likelihood estimation of latent interaction effects with the LMS method. Psychometrika, 65(4), 457-474. https://doi.org/10.1007/BF02296338.

Liem, G. A. D., Ginns, P., Martin, A. J., Stone, B., \& Herrett, M. (2012). Personal best goals and academic and social functioning: a longitudinal perspective. Learning and Instruction, 22(3), 222-230. https://doi. org/10.1016/j.learninstruc.2011.11.003.

Litalien, D., \& Guay, F. (2015). Dropout intentions in PhD studies: a comprehensive model based on interpersonal relationships and motivational resources. Contemporary Educational Psychology, 41, $218-231$. https://doi.org/10.1016/j.cedpsych.2015.03.004.

Little, T. D., Bovaird, J. A., \& Widaman, K. F. (2006). On the merits of orthogonalizing powered and product terms: implications for modeling interactions among latent variables. Structural Equation Modeling, 13(4), 497-519. https://doi.org/10.1207/s15328007sem1304 1.

Locke, E. A., \& Latham, G. P. (2002). Building a practically useful theory of goal setting and task motivation. American Psychologist, 57(9), 705-717. https://doi.org/10.1037//0003-066X.57.9.705. 
Lundquist, C., Spalding, R. J., \& Landrum, R. E. (2002). College student's thoughts about leaving the university: the impact of faculty attitudes and behaviors. Journal of College Student Retention: Research, Theory \& Practice, 4(2), 123-133. https://doi.org/10.2190/FLAL-7AM5-Q6K3-L40P.

Lüftenegger, M., \& Chen, A. J. (2017). Conceptual issues and assessment of implicit theories. Zeitschrift für Psychologie, 225(2), 99-106. https://doi.org/10.1027/2151-2604/a000286.

Marsh, H. W., Hau, K. T., \& Wen, Z. (2004). In search of golden rules: comment on hypothesis-testing approaches to setting cutoff values for fit indexes and dangers in overgeneralizing $\mathrm{Hu}$ and Bentler's (1999) findings. Structural Equation Modeling, 11(3), 320-341. https://doi.org/10.1207/s15328007 sem1103_2.

Martin, A. J. (2006). Personal bests (PBs): a proposed multidimensional model and empirical analysis. British Journal of Educational Psychology, 76(4), 803-825. https://doi.org/10.1348/000709905X55389.

Martin, A. J. (2011). Personal best (PB) approaches to academic development: implications for motivation and assessment. Educational Practice and Theory, 33(1), 93-99. https://doi.org/10.7459/ept/33.1.06.

Martin, A. J. (2013). Goal setting and personal best goals. In J. Hattie \& E. M. Anderman (Eds.), International guide to student achievement (pp. 356-358). New York: Routledge.

Martin, A. J., \& Elliot, A. J. (2016). The role of personal best (PB) goal setting in students' academic achievement gains. Learning and Individual Differences, 45, 222-227. https://doi.org/10.1016/j. lindif.2015.12.014.

Martin, A. J., \& Liem, G. A. (2010). Academic personal bests (PBs), engagement, and achievement: a crosslagged panel analysis. Learning and Individual Differences, 20(3), 265-270. https://doi.org/10.1016/j. lindif.2010.01.001.

Martin, A. J., Durksen, T. L., Williamson, D., Kiss, J., \& Ginns, P. (2014). Personal best (PB) goal setting and students' motivation in science: A study of science valuing and aspirations. The Educational and Developmental Psychologist, 31(2), 85-96. https://doi.org/10.1017/edp.2014.19.

Martin, A. J., Collie, R. J., Mok, M. M. C., \& McInerney, D. M. (2016). Personal best (PB) goal structure, individual PB goals, engagement, and achievement: a study of Chinese- and English-speaking background students in Australian schools. British Journal of Educational Psychology, 86(1), 75-91. https://doi. org/10.1111/bjep.12092.

Mashburn, A. J. (2000). A psychological process of college student dropout. Journal of College Student Retention, 2(3), 173-190. https://doi.org/10.2190/U2QB-52J9-GHGP-6LEE.

Maslowsky, J., Jager, J., \& Hemken, D. (2015). Estimating and interpreting latent variable interactions: a tutorial for applying the latent moderated structural equations method. International Journal of Behavioral Development, 39(1), 87-96. https://doi.org/10.1177/0165025414552301.

Muthén, B. (2012). Latent variable interactions. Retrieved from http://www.statmodel.com/download/LV\%20 Inter action.pdf

Muthén, B., \& Muthén, L. K. (1998-2015). Mplus (Version 7.3). Los Angeles, CA: Muthén \& Muthén.

O'Keeffe, P. (2013). A sense of belonging: improving student retention. College Student Journal, 47(4), $605-613$.

Ozga, J., \& Sukhnandan, L. (1998). Undergraduate non-completion: developing an explanatory model. Higher Education Quarterly, 52(3), 316-333. https://doi.org/10.1111/1468-2273.00100.

Patzak, A., Kollmayer, M., \& Schober, B. (2017). Buffering impostor feelings with kindness: The mediating role of self-compassion between gender-role orientation and the impostor phenomenon. Frontiers in Psychology, 8(1289). https://doi.org/10.3389/fpsyg.2017.01289.

Pleskac, T. J., Keeney, J., Merritt, S. M., Schmitt, N., \& Oswald, F. L. (2011). A detection model of college withdrawal. Organizational Behavior and Human Decision Processes, 115(1), 85-98. https://doi. org/10.1016/j.obhdp.2010.12.001.

Robbins, S. B., Lauver, K., Le, H., Davis, D., Langley, R., \& Carlstrom, A. (2004). Do psychosocial and study skill factors predict college outcomes? A meta-analysis. Psychological Bulletin, 130(2), 261-288. https://doi. org/10.1037/0033-2909.130.2.261.

Rump, M., Esdar, W., \& Wild, E. (2017). Individual differences in the effects of academic motivation on higher education students' intention to drop out. European Journal of Higher Education, 7(4), 341-355. https://doi. org/10.1080/21568235.2017.1357481.

Ryan, J. F. (2004). The relationship between institutional expenditures and degree attainment at baccalaureate colleges. Research in Higher Education, 45(2), 97-114. https://doi.org/10.1023 /B:RIHE.0000015691.02545.61.

Satorra, A. (2000). Scaled and adjusted restricted tests in multi-sample analysis of moment structures. In R. D. H. Heijmans, D. S. G. Pollock, \& A. Satorra (Eds.), Innovations in multivariate statistical analysis. A Festschrift for Heinz Neudecker (pp. 233-247). London: Kluwer Academic Publishers. https://doi. org/10.1007/978-1-4615-4603-0_17. 
Satorra, A., \& Bentler, P. M. (2001). A scaled difference chi-square test statistic for moment structure analysis. Psychometrika, 66(4), 507-514. https://doi.org/10.1007/BF02296192.

Schiefele, U., Streblow, L., \& Brinkmann, J. (2007). Aussteigen oder Durchhalten. Was unterscheidet Studienabbrecher von anderen Studierenden? [Dropping out or persevering: What distinguishes university dropouts from other students?]. Zeitschrift für Entwicklungspsychologie und Pädagogische Psychologie, 39(3), 127-140. https://doi.org/10.1026/0049-8637.39.3.127.

Skaalvik, E. M., \& Skaalvik, S. (2013). School goal structure: associations with students' perceptions of their teachers as emotionally supportive, academic self-concept, intrinsic motivation, effort, and help seeking behavior. International Journal of Educational Research, 61, 5-14. https://doi.org/10.1016/j. ijer.2013.03.007.

Suhlmann, M., Sassenberg, K., Nagengast, B., \& Trautwein, U. (2018). Belonging mediates effects of studentuniversity fit on well-being, motivation, and dropout intention. Social Psychology, 49(1), 16-28. https://doi. org/10.1027/1864-9335/a000325.

Suhre, C. J., Jansen, E. P., \& Torenbeek, M. (2013). Determinants of timely completion: the impact of bachelor's degree programme characteristics and student motivation on study progress. Higher Education Research \& Development, 32(3), 479-492. https://doi.org/10.1080/07294360.2012.684374.

Tinto, V. (1975). Dropout from higher education: a theoretical synthesis of recent research. Review of Educational Research, 45(1), 89-125. https://doi.org/10.3102/00346543045001089.

Tinto, V. (1987). Leaving college: rethinking the causes and cures of student attrition. Chicago: University of Chicago Press.

Tinto, V. (2006). Research and practice of student retention: What next? Journal of College Student Retention: Research, Theory and Practice, 8(1), 1-19. https://doi.org/10.2190/C0C4-EFT9-EG7W-PWP4.

Titus, M. A. (2004). An examination of the influence of institutional context on student persistence at 4-year colleges and universities: A multilevel approach. Research in Higher Education, 45, 673-699. https://doi. org/10.1023/B:RIHE.0000044227.17161.fa.

Vossensteyn, J. J., Kottmann, A., Jongbloed, B. W. A., Kaiser, F., Cremonini, L., Stensaker, B., ... Wollscheid, S. (2015). Dropout and completion in higher education in Europe: main report. Luxembourg: European Union. https://doi.org/10.2766/826962.

Wilcox, P., Winn, S., \& Fyvie-Gauld, M. (2005). 'It was nothing to do with the university, it was just the people': The role of social support in the first-year experience of higher education. Studies in Higher Education, 30, 707-722. https://doi.org/10.1080/03075070500340036.

Woodard, D., Mallory, S., \& De Luca, A. (2001). Retention and institutional effort: A self-study framework. NASPA Journal, 39, 53-83. https://doi.org/10.2202/1949-6605.1159.

Zając, T. Z., \& Komendant-Brodowska, A. (2019). Premeditated, dismissed and disenchanted: higher education dropouts in Poland. Tertiary Education and Management, 25(1), 1-16. https://doi.org/10.1007/s11233-01809010-z

Zimmerman, B. J., \& Moylan, A. R. (2009). Self-regulation: where metacognition and motivation intersect. In D. J. Hacker, J. Dunlosky, \& A. C. Graesser (Eds.), Handbook of metacognition in education (pp. 299-315). New York: Routledge.

Publisher's note Springer Nature remains neutral with regard to jurisdictional claims in published maps and institutional affiliations.

Lisa Bardach. University of York, Department of Education, York, YO10 5DD, UK. E-mail: lisa.bardach@york.ac.uk

Current themes of research:

Non-cognitive attributes. Motivation. Goal structures. (Social) emotions aspects of learning and instruction.

Most relevant publications in the field of Psychology of Education:

Bardach, L., Lüftenegger, M., Yanagida, T., Spiel, C., \& Schober, B. (2019). Achievement or agreement - Which comes first? Clarifying the temporal ordering of achievement and within-class consensus on classroom goal structures. Learning and Instruction, 61, 72-83. https://doi.org/10.1016/j.learninstruc.2019.01.003 
Bardach, L., Khajavy, G.H., Hamedi, S.M., Schober, B., \& Lüftenegger, M. (2018). Student-teacher agreement on classroom goal structures and potential predictors. Teaching and Teacher Education, 74, 249-260. https://doi.org/10.1016/j.tate.2018.05.010

Bardach, L., Lüftenegger, M., Yanagida, T., Spiel, C., \& Schober, B. (2018). The role of within-class consensus on mastery goal structures in predicting socio-emotional outcomes. British Journal of Educational Psychology. https://doi.org/10.1111/bjep.12237

Marko Lüftenegger. University of Vienna, Centre for Teacher Education, Department for Teacher Education, Porzellangasse 4, 1090, Vienna, Austria. E-mail: marko.lueftenegger@univie.ac.at

Current themes of research:

Motivation and emotions in education. High ability and giftedness. Classroom environments that facilitate students' (positive) development. Evaluation of educational programs.

Most relevant publications in the field of Psychology of Education:

Lüftenegger, M., \& Chen, A. J. (2017). Implicit theories. International perspectives from multiple domains. Zeitschrift für Psychologie, 225(2), 97-98. https://doi.org/10.1027/2151-2604/a000285

Lüftenegger, M., Van de Schoot, R., Schober, B., Finsterwald, M., \& Spiel, C. (2014). Promotion of students' mastery goal orientations: does TARGET work? Educational Psychology, 34(4), 451-469. https://doi. org/10.1080/01443410.2013.814189

Lüftenegger, M., Schober, B., Van de Schoot, R., Wagner, P., Finsterwald, M., \& Spiel, C. (2012). Lifelong learning as a goal - do autonomy and self-regulation in school result in well prepared pupils? Learning and Instruction, 22, 27-36. https://doi.org/10.1016/j.learninstruc.2011.06.001

Sophie Ozlon. University of Vienna, Centre for Teacher Education, Department for Teacher Education, Porzellangasse 4, 1090, Vienna, Austria. E-mail:sophie.oczlon@univie.ac.at

Current themes of research:

Goal structures. (Social) Emotions. Acculturation of adolescents.

Most relevant publications in the field of Psychology of Education:

Janke, S., Bardach, L., Oczlon, S., \& Lüftenegger M. (2019). Enhancing feasibility when measuring teachers' motivation: A brief scale for teachers' achievement goal orientations. Teaching and Teacher Education, 83, 111. https://doi.org/10.1016/j.tate.2019.04.003

Christiane Spiel. University of Vienna, Faculty of Psychology, Department of Applied Psychology: Work, Education, and Economy, Universitätsstraße 7, 1010 Vienna, Austria. E-mail:christiane.spiel@univie.ac.at

Current themes of research:

Lifelong learning. Bullying. Evaluation research.

Most relevant publications in the field of Psychology of Education: 
Spiel, C., Schober, B., \& Strohmeier, D. (2016). Implementing intervention research into public policy - the "I3Approach". Prevention Science, 1-10. https://doi.org/10.1007/s11121-016-0638-3

Spiel, C., \& Strohmeier, D. (2011). National strategy for violence prevention in the Austrian public school system: development and implementation. International Journal of Behavioral Development, 35, 412-418. https://doi.org/10.1177/0165025411407458

Spiel, C., Salmivalli, C., \& Smith, P. K. (2011). Translational research: national strategies for violence prevention in school. International Journal of Behavioral Development, 35, 381-382. https://doi.org/10.1007/s11292012-9142-3

Barbara Schober. University of Vienna, Faculty of Psychology, Department of Applied Psychology: Work, Education, and Economy, Universitätsstraße 7, 1010 Vienna, Austria. E-mail:barbara.schober@univie.ac.az

Current themes of research:

Motivation. Transfer and implementation research. Lifelong learning. Self-regulation.

Most relevant publications in the field of Psychology of Education:

Schober, B., Klug, J., Jöstl, G., Spiel, C., Dresel, M., Steuer, G., Schmitz, B., \& Ziegler, A. (2015). Gaining substantial new insights into University Students' SRL-Competences - what do we need to succeed? In: S. Blömeke, J. E. Blömeke and R. Shavelson: Special Issue Assessment of Competencies in Higher Education. Zeitschrift für Psychologie/Journal of Psychology, 222(1), S. 64-65. https://doi.org/10.1027/2151-2604 /a000201

Schober, B., Lüftenegger, M., Wagner, P., Finsterwald, M. \& Spiel, C. (2013). Facilitating lifelong learning in school-age learners. Programs and recommendations. European Psychologist, 18(2), 114-125. https://doi. org/10.1027/1016-9040/a000129

Spiel, C., Schober, B., Strohmeier, D. \& Finsterwald, M. (2011). Cooperation among researchers, policy makers, administrators, and practitioners: challenges and recommendations. ISSBD Bulletin, 2(60), 11-14. 